\title{
SIMULAÇÃO NUMÉRICA APLICADA AO ESTUDO DA RELAÇÃO ENTRE LARGURA DE CONTATO DA MATRIZ E O ALONGAMENTO NO FORJAMENTO EM MATRIZ ABERTA*
}

Kíssia Carolina Bertoluci Cardoso ${ }^{1}$ Murillo Henrique de Mello Peteffi ${ }^{2}$ Rodrigo Prestes Limberger ${ }^{3}$ Luana De Lucca de Costa 4 Lirio Schaeffer ${ }^{5}$

\section{Resumo}

Para a fabricação de peças de grande porte, o forjamento em matriz aberta é o processo mais utilizado. Porém, se seus parâmetros não forem bem estabelecidos, defeitos metalúrgicos poderão surgir; esses, em sua maioria, provindos do material bruto de fusão, como rechupes e vazios. Para sanar tais defeitos, a deformação imposta na peça deve ser a mais homogênea possível. Neste estudo, a simulação numérica foi utilizada para verificar a relação entre a largura de contato matriz-peça e a espessura da parede de peças vazadas, com o objetivo de analisar o conceito de razão de mordida para esse tipo de geometria. Utiliza-se um billet cilíndrico inicial de $450 \mathrm{~mm}$ de comprimento, $360 \mathrm{~mm}$ de diâmetro externo e $120 \mathrm{~mm}$ de diâmetro interno, de material AISI 4140. As razões de mordida estudadas variam entre 0,2 e 1,4 , sendo impostas variações de tempo em cada processo. Após análise, pôde-se verificar que as geometrias que apresentam distribuições mais homogêneas de deformação utilizaram razão de mordida de 0,4.

Palavras-chave: Forjamento a quente; Matriz aberta; Simulação numérica.

\section{NUMERICAL APPLIED TO THE RELATIONSHIP BETWEEN THE STUDY OF CONTACT WIDTH OF MOTHER AND THE STRETCH IN FORGING OPEN IN MOTHER}

\section{Abstract}

For the manufacture of large parts, the open die forging is the most widely used process. But if its parameters are not well established, metallurgical defects may appear; these, mostly stemmed raw material in consequence of the casting process, such as cavities and voids. To solve these defects, the deformation imposed in the workpiece should be as homogeneous as possible. In this study numerical simulation was used to investigate the relationship between die-workpiece contact width and the wall thickness of the hollow workpieces analyzing the concept of bite ratio for this type of geometry. It uses an initial cylindrical hollow billet of AISI 4140 with $450 \mathrm{~mm}$ in length, $360 \mathrm{~mm}$ in outer diameter and $120 \mathrm{~mm}$ in internal diameter. The studied bite ratios range from 0.2 to 1.4 , and time variations are imposed in each case. After the analysis, it was observed that geometries that have more homogeneous distributions of strain used a bite ratio of 0.4 .

Keywords: Hot forging; Open die; Numerical simulation.

${ }^{1}$ Graduanda, Eng. Metalúrgica, Laboratório de Transformação Mecânica, Universidade Federal do Rio Grande do Sul (UFRGS), Porto Alegre, Rio Grande do Sul, Brasil.

${ }^{2}$ Graduando, Eng. Mecânica, Laboratório de Transformação Mecânica, UFRGS, Porto Alegre, RS, Brasil.

${ }^{3}$ Eng. Mecânico, Mestrando, Programa de Pós-Graduação em Eng. de Minas, Metalurgia e Materiais (PPGE3M), UFRGS, Porto Alegre, RS, Brasil.

${ }^{4}$ Eng. Mecânica, Mestre em Engenharia, Doutoranda, PPGE3M, UFRGS, Porto Alegre, RS, Brasil.

${ }^{5}$ Dr. Ing., Laboratório de Transformação Mecânica, UFRGS, Porto Alegre, RS, Brasil. 


\section{INTRODUÇÃO}

O potencial de geração de energia a partir de fontes eólicas avançou na matriz energética mundial através de investimentos e incentivos na utilização de alternativas renováveis. Com isso, o emprego de aerogeradores cresceu na última década, influenciando no desenvolvimento de tecnologia e de novos estudos que acrescem seu desempenho. O custo para confecção desses equipamentos é alto quando comparado aos recursos tradicionais de geração, ao exemplo das termoelétricas e das hidroelétricas, inviabilizando sua expansão em ritmo acelerado. Por esse motivo, pesquisas de melhoria dos seus componentes são desenvolvidas continuamente, visando principalmente reduzir a quantidade de matéria prima e prolongar a vida útil de seus sistemas.

Um dos principais alvos de estudos são os eixos responsáveis pela transmissão do movimento das pás do gerador ao rotor. Estes são componentes produzidos normalmente pelo processo de fundição, devido às suas dimensões e geometrias. Entretanto, o processo ocasiona o surgimento de inclusões e de porosidades no interior da estrutura após a solidificação, podendo levar ao surgimento de trincas após longos períodos de exposição aos carregamentos cíclicos, causando assim, a falha do componente. A substituição do processo de fundição pelo processo de forjamento em matriz aberta visa propriedades mecânicas de melhor desempenho.

O forjamento em matriz aberta tende a reduzir os defeitos internos, proporcionando melhorias nas características final do produto [1]. Segundo Chen et al. [2], entre as qualidades do processo está o fechamento dos vazios provenientes do estado bruto de fusão e a homogeneização microestrutural da peça. Kakimoto [3], afirma que 75 $\%$ do fechamento de vazios ocorre através de processos de compressão, evidenciando a importância do controle da deformação no forjamento.

Entretanto, é de extrema importância a escolha certa dos parâmetros do processo, como a configuração das matrizes, o comprimento das mesmas, a redução aplicada a cada passe, o avanço e o gradiente de temperatura $[4,5]$.

$\mathrm{O}$ avanço é o quanto se movimenta longitudinalmente a ferramenta em relação à peça após uma mordida, ou uma série delas na mesma região, caso haja rotação da peça. A mordida é o movimento que a prensa realiza para conformar o material. A Figura 1 apresenta os principais componentes e parâmetros do forjamento em matriz aberta.

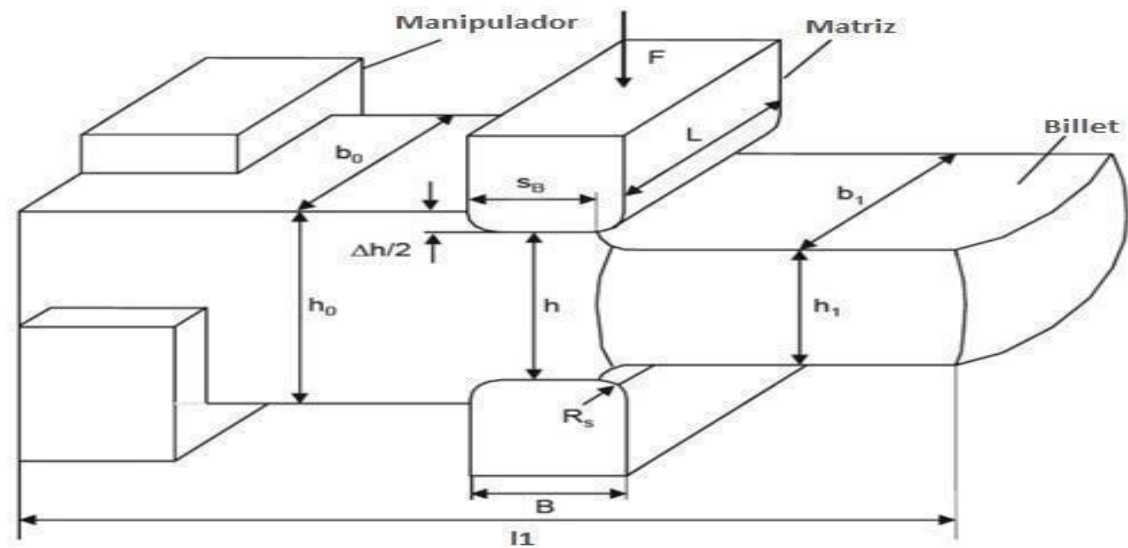

\begin{tabular}{|cl|}
\hline ho,h1 & $\begin{array}{l}\text { Alturas antes e } \\
\text { depois da deformaçao }\end{array}$ \\
\hline bo,b1 & $\begin{array}{l}\text { Comprimentos } \\
\text { antes e depois da } \\
\text { deformação }\end{array}$ \\
\hline B,L & $\begin{array}{l}\text { Largura e } \\
\text { comprimento da matriz }\end{array}$ \\
\hline Rs & $\begin{array}{l}\text { Raio da curvatura da } \\
\text { matriz }\end{array}$ \\
\hline F & $\begin{array}{l}\text { Forca aplicada pela } \\
\text { matriz }\end{array}$ \\
\hline S & $\begin{array}{l}\text { Largura de contato } \\
\text { entre a matriz e a peça }\end{array}$ \\
\hline
\end{tabular}

Figura 1. Sistemática do forjamento incremental em matriz aberta [6]. 
Em relação às deformações, pode-se considerar que, quando baixas, atingem a peça apenas superficialmente e demandam mais tempo de processo. Enquanto grandes deformações, além de exigirem forças de forjamento maiores, podem alterar a geometria da peça irreversivelmente. Chen et al. [2], citam que faixas de deformação entre 20 e $25 \%$ são ideais para o fechamento de vazios, e que dificuldades de deformações uniformes na zona próxima ao eixo de peças maciças podem ser sanadas quando conformadas com a utilização de rotações de $90^{\circ}$ entre sucessivas mordidas.

A razão de mordida é o parâmetro que relaciona a largura de contato ferramentapeça com a altura inicial da peça $\left(S_{B} / h_{0}\right)$. Essa relação guia o forjamento de peças maciças em relação às distribuições de deformações no seu interior [1].

Relações pequenas, na ordem de 0,2, aumentam o tempo de processo, devido à necessidade do maior número de mordidas, ocasionando perdas térmicas significativas. Com essa relação, ocorrem mudanças puramente geométricas da peça, pois as deformações atingem apenas sua superfície, enquanto o núcleo permanece inalterado. Também são vistas tensões trativas no núcleo, o que pode gerar o aumento dos vazios provenientes do estado bruto da peça.

Quando a relação é elevada a ordem de 1, têm-se mordidas de grandes superfícies de contato, aumentando a força necessária no processo, assim como o atrito entre peça e ferramenta. A força disponível na prensa de forjamento pode se tornar limitante neste caso. Além dos dois fatores citados, uma razão de mordida grande causa distribuições heterogênicas de deformações, gerando zonas não deformadas, que continuam passíveis de defeitos metalúrgicos.

A Figura 2 apresenta três distintas razões de mordida $(0,3,0,5$ e 0,8) para uma peça maciça. É possível verificar a influência desse parâmetro como descrito anteriormente.

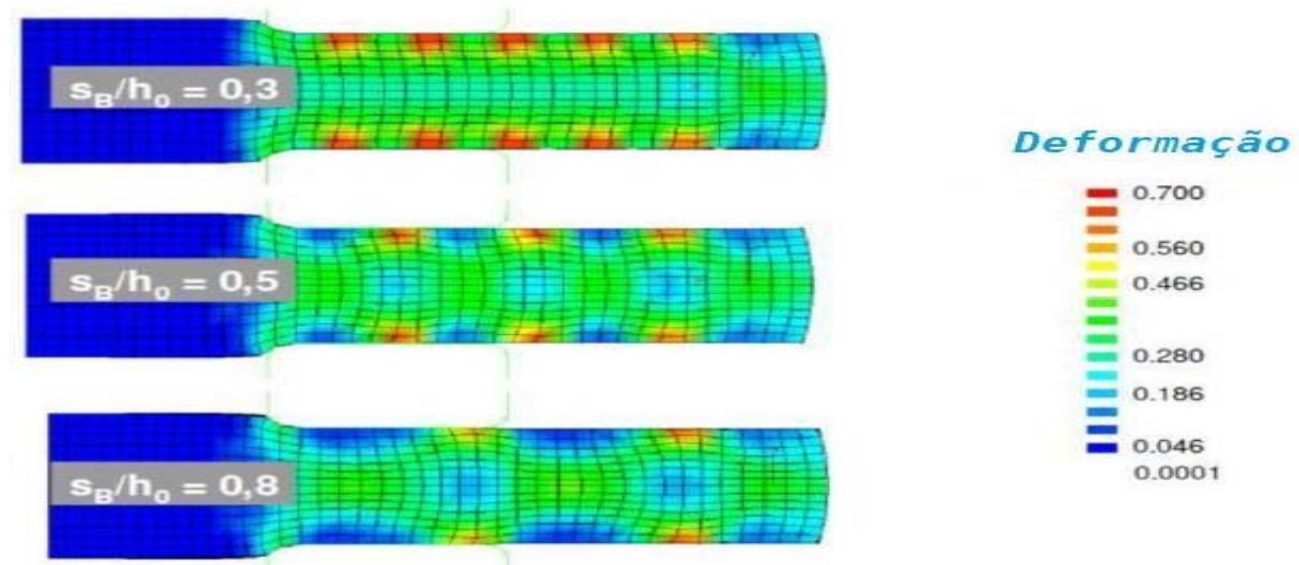

Figura 2. Distribuições de deformações com diferentes razões de mordida [8].

Analisando a Figura 2, vê-se que um valor intermediário de razão de mordida, aproximadamente 0,5 , é favorável no que diz respeito à deformação no núcleo da peça. Shah [7] e Wolske [8] também citam resultados de homogeneização da deformação no núcleo e fechamentos de vazios para valores entre 0,5 e 0,8.

A Figura 3 apresenta as deformações resultantes quando utilizados diferentes avanços da ferramenta ao longo do processo. No gráfico da Figura 3, em A, pode-se observar as zonas não afetadas pelo forjamento devido ao grande avanço da matriz após cada mordida. Na Figura 3 , em B, é possível verificar que todas as zonas são deformadas quando o avanço é ajustado. 


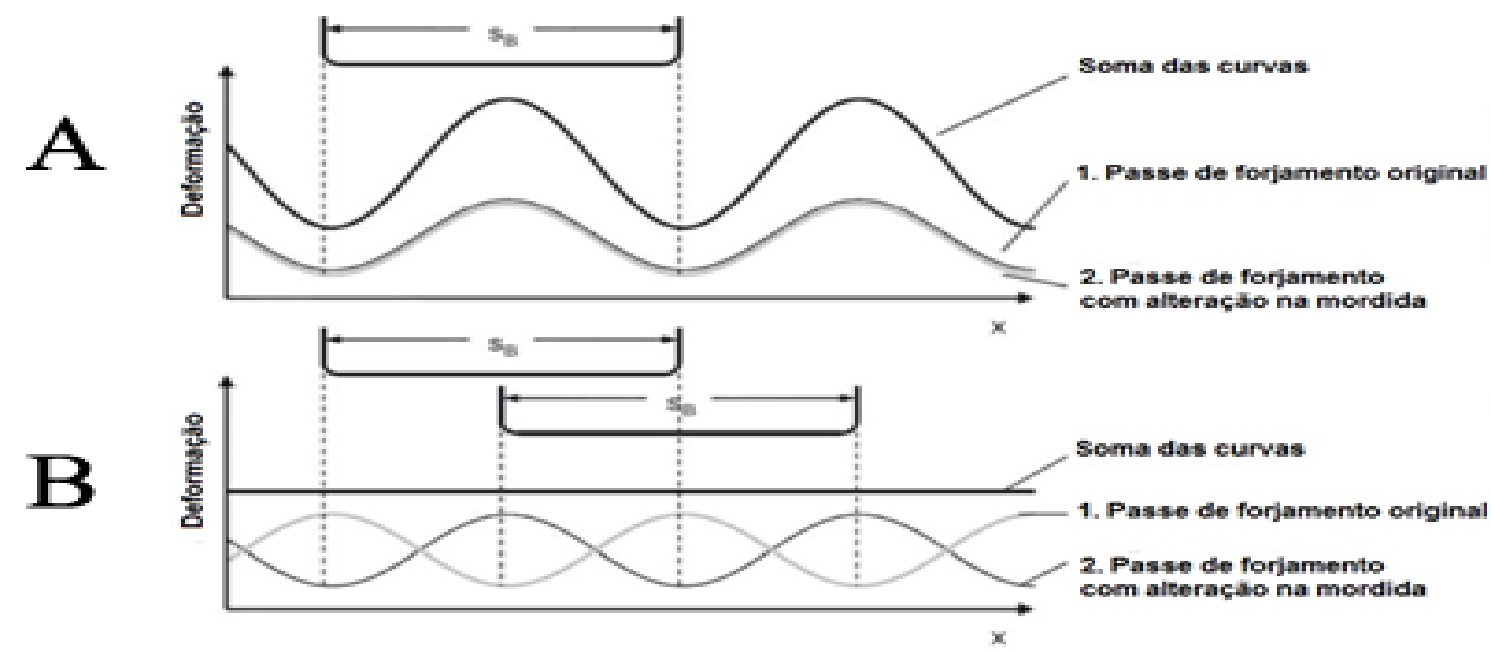

Figura 3. Somatório de deformações para diferentes avanços [8].

Spur [9], analisou a mudança do avanço da ferramenta, alterando de uma mordida inicial com grande superfície de contato entre a ferramenta e a peça, Figura 4, em A, para mordidas posteriores mais curtas em $B$ da figura 4 . A segunda seção da peça, junto ao ponto central do eixo $\mathrm{X}$, evidencia a falta de deformação no núcleo da peça (cor cinza escuro).

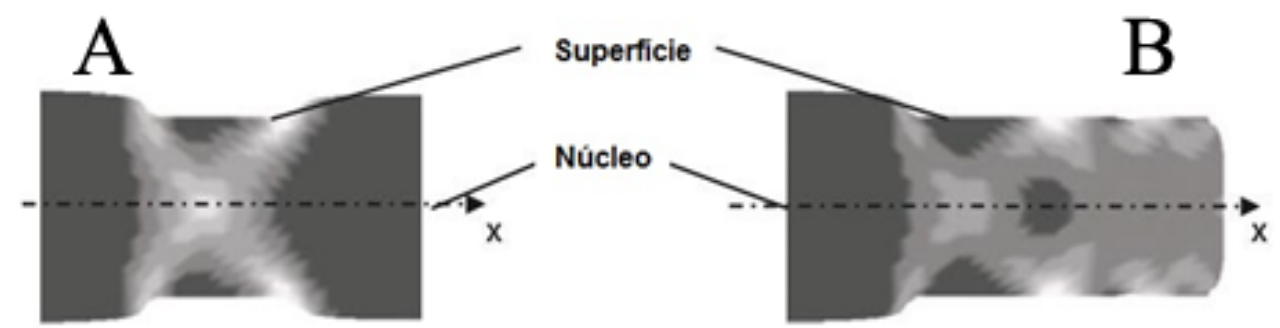

Figura 4. Distribuição de deformações quando alterado o avanço ao longo do forjamento [9].

No entanto, a literatura pouco aborda alternativas que tratam de peças vazadas. Principalmente em relação à quais valores os parâmetros devem ser relacionados e se os comumente utilizados para peças maciças podem ser equivalentes nos processos com peças vazadas.

Para que as propriedades mecânicas da peça sejam satisfatórias, o presente trabalho estuda homogeneizar as deformações no interior de peças cilíndricas vazadas, aprimorando a relação da razão de mordida através de simulações numéricas computacionais.

\section{MATERIAIS E MÉTODOS}

O billet inicial possui comprimento de $450 \mathrm{~mm}$, diâmetro externo de $360 \mathrm{~mm}$ e 120 $\mathrm{mm}$ de diâmetro interno. As matrizes possuem $450 \mathrm{~mm}$ de comprimento e $200 \mathrm{~mm}$ de largura. $O$ mandril apresenta conicidade de $0,3^{\circ}$ ao longo de seu comprimento, que é de $1200 \mathrm{~mm}$, e possui diâmetro maior de $120 \mathrm{~mm}$. A Figura 5 apresenta a posição relativa entre os componentes do processo. 


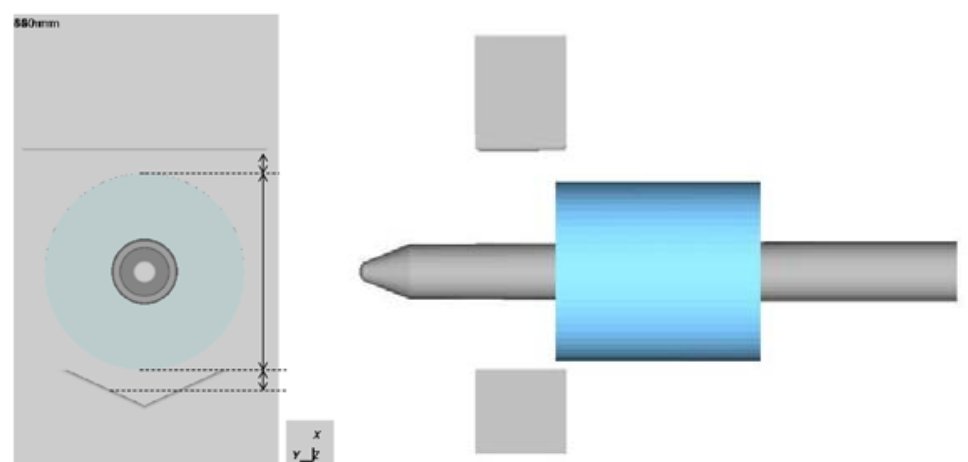

Figura 5. Vista frontal e lateral da disposição dos componentes.

Reproduzidos no software Simufact. forming 12, todos os processos contam com o mesmo conjunto de componentes e condições iniciais, diferenciando-se apenas no que se refere à cinemática.

Foram realizadas variações nas razões de mordida, entre 0,2 e 1,4, sendo h0 definido como a espessura de parede do billet, que mede $120 \mathrm{~mm}$.

A Tabela 1 apresenta os valores das razões de mordida utilizados quando ho é 120 $\mathrm{mm}$. Aplicando esses valores no cálculo de razão de mordida, obtêm-se os valores do contato da ferramenta com a peça $\left(S_{B}\right)$. A partir desse valor, pode-se estimar o número de avanços para que $85 \%$ da peça, $384 \mathrm{~mm}$, sejam deformados. Para certificar que todas as simulações deformem o mesmo comprimento da peça, $\mathrm{Sb}$ iniciais foram utilizados em algumas simulações, o que não altera a análise do resultado. Ao todo, o processo conta com sete variações da relação $S_{B} / h o c o m$ intervalos iguais entre os valores.

Tabela 1. Valores das razões de mordida, avanços, $S b$ e total de passes.

\begin{tabular}{ccccc}
\hline $\mathrm{Sb} / \mathrm{h} 0$ & $\mathrm{Sb}(\mathrm{mm})$ & Avanços & Sb inicial $(\mathrm{mm})$ & Total passes \\
\hline 0,2 & 24 & 16 & 24 & 16 \\
0,4 & 48 & 8 & 48 & 8 \\
0,6 & 72 & 5 & 24 & 6 \\
0,8 & 96 & 4 & 96 & 4 \\
1,0 & 120 & 3 & 24 & 4 \\
1,2 & 144 & 2 & 96 & 3 \\
\hline 1,4 & 168 & 2 & 48 & 3 \\
\hline
\end{tabular}

No processo, um giro é definido por um conjunto de 10 mordidas que ocorrem sem que haja movimentos longitudinais das matrizes em relação à peça, conforme a Figura 6. Durante um giro e antes de cada mordida, há uma rotação de $90^{\circ}$ da peça em relação às matrizes. Apenas uma vez, após a quinta mordida de cada giro, uma rotação de $45^{\circ}$ é realizada, a fim de retomar a geometria circular da peça. 

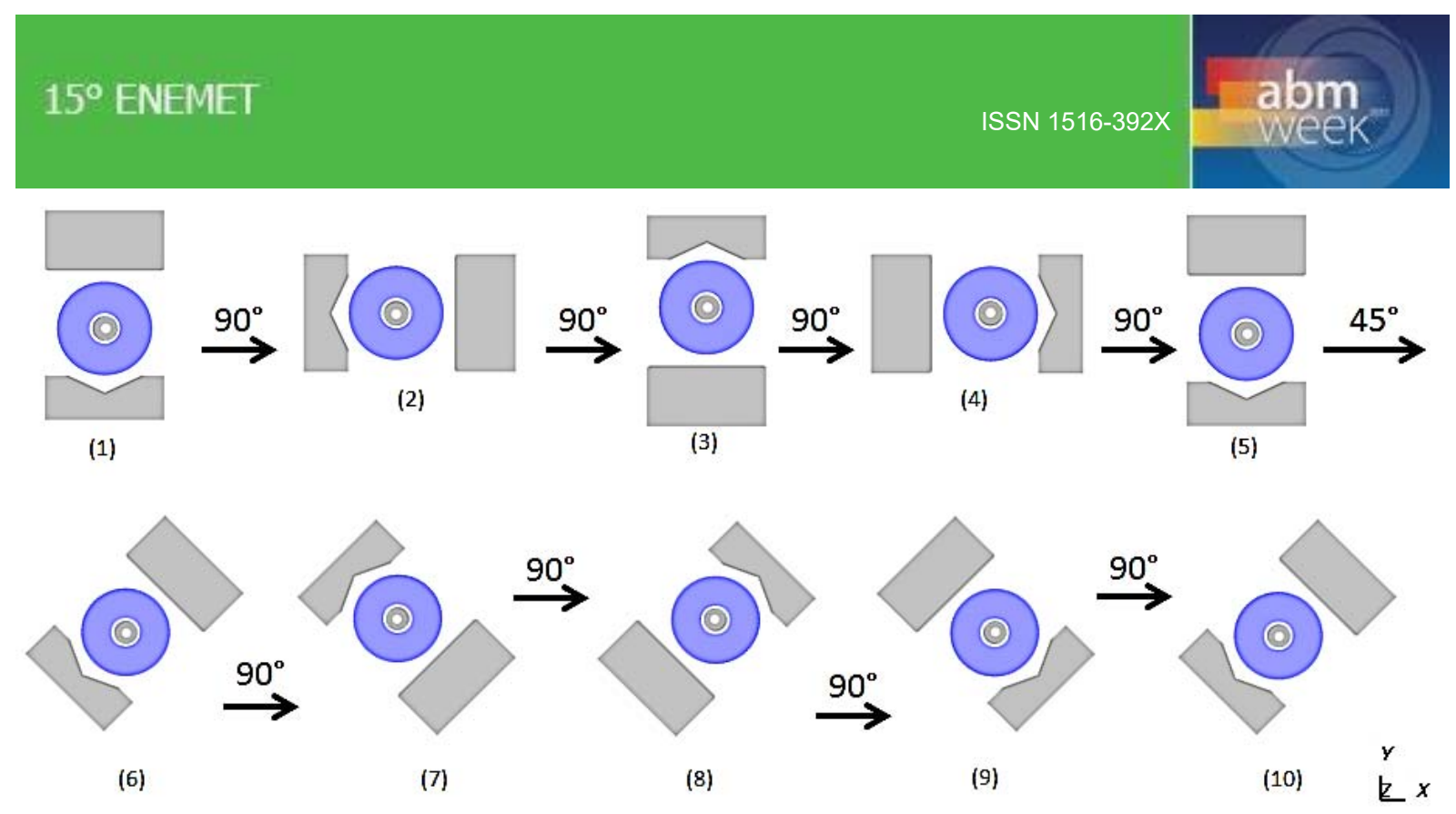

Figura 6. Sequência de mordidas a cada giro.

A cinemática deste processo apresenta apenas uma matriz móvel, plana, com velocidade igual a $80 \mathrm{~mm} / \mathrm{s}$, uma matriz em $\vee$ fixa e um mandril que não apresenta resistência ao movimento da peça, tendo apenas o papel de manter a geometria interna da peça inalterada e a trazer novamente até a sua posição original após a deformação. A peça é de aço AISI 4140 e tem temperatura inicial de $1200^{\circ} \mathrm{C}$. As matrizes, bem como o mandril, são fabricadas em aço AISI H13 e têm temperatura inicial de $300^{\circ} \mathrm{C}$.

\section{RESULTADOS E DISCUSSÃO}

Em uma abordagem inicial, poderia ser considerado que o mandril agisse como uma ferramenta de deformação. Isso implicaria em uma situação onde o mesmo trabalharia como uma matriz inferior, causando uma força de reação no material que está sendo deformado. Com isso, pode-se analisar cada uma das duas partes geradas pelo corte de uma seção longitudinal como um caso isolado. Assim, cada uma destas equivaleria ao forjamento de uma peça maciça independente e, ao se observar os resultados, seriam encontrados os padrões de comportamento vistos na Figura 2.

A partir dos resultados das simulações, apresentados na Figura 7, pôde-se observar que as deformações tendem a adotar um padrão diferente, induzindo um visual semelhante ao que se esperaria de um eixo completamente maciço, considerando assim que as superfícies que sofrem o contato das matrizes fossem os delimitadores para a formação dos padrões "X". Porém, uma vez que o mandril é indeformável no processo e a área de contato deste com a peça é maior que o das matrizes, tem-se uma força de atrito que dificulta o fluxo de material na região, assim a formação do padrão de deformação dos eixos maciços não pode ser obtido. 

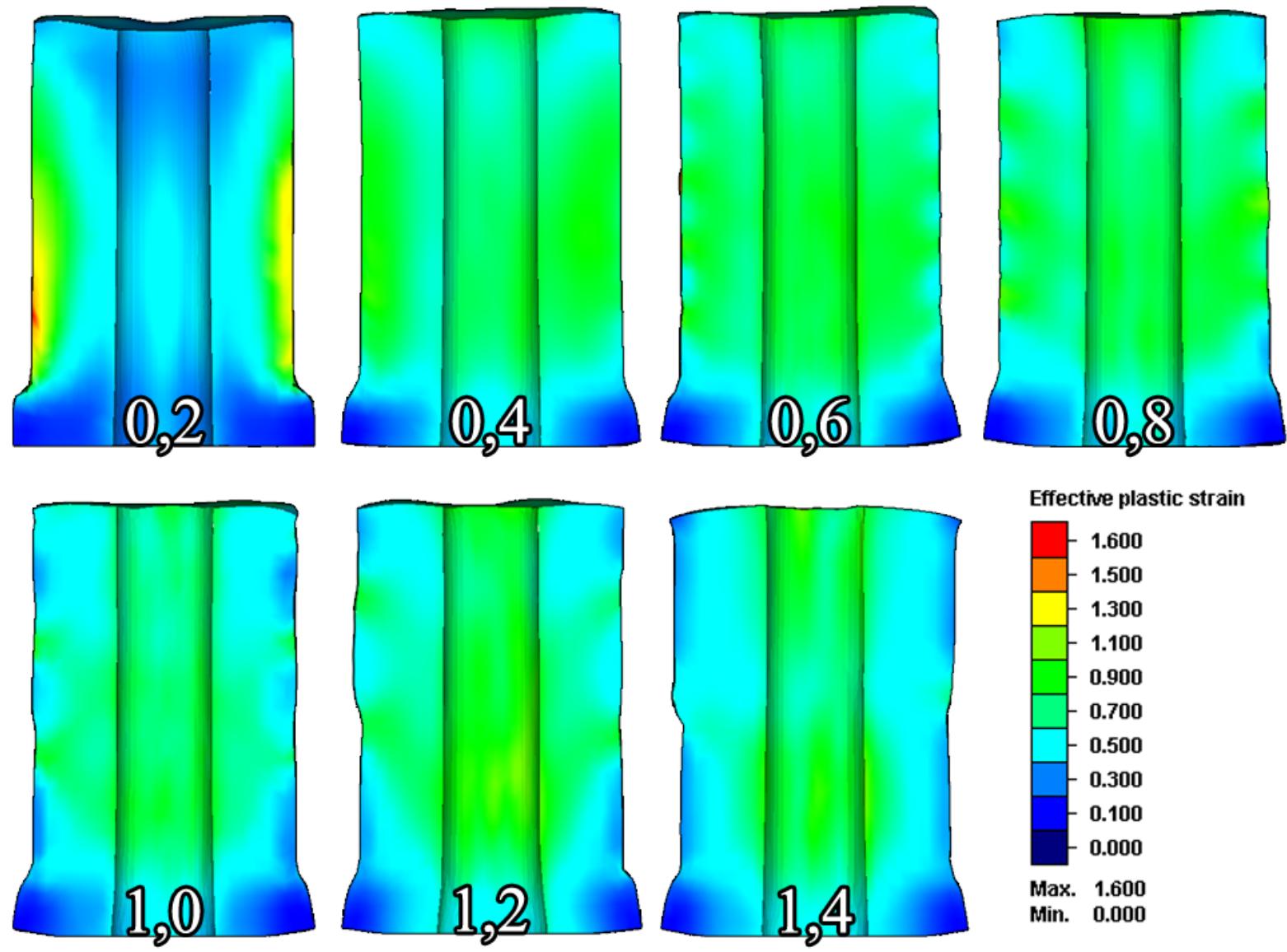

Figura 7. Distribuição de deformações para as diferentes relações de mordida.

Analisando as distribuições de deformação, percebe-se que quando utilizadas razões de mordida igual 0,4 têm-se quantidades de deformação efetiva homogênea ao longo da parte forjada.

Embora tenha similaridade com o padrão de propagação de deformação em peças maciças, os valores ideais de razão $S_{B} / h o$ não são correspondentes para os dois tipos de processos. Em peças maciças, a busca por homogeneidade e por deformação no núcleo da peça utiliza valores entre 0,5 e 0,8, que quando aplicada em eixos vazados, induziram deformações maiores na região próxima ao mandril, enquanto a superfície foi pouco deformada.

O núcleo, para o qual se buscam as propriedades homogêneas finais do forjado, pode ser considerado, neste caso, como uma distância média entre a parede interna e a externa. Deste modo, a razão de mordida ideal para o processo se encontra numa faixa na qual, se utilizada em eixos maciços, apresentaria as propriedades desejadas numa região mais superficial da peça.

Contudo, a utilização de razões de mordida menores implica em um maior tempo de processo, ocasionando maiores perdas térmicas na peça, conforme mostra a Figura 8. Este fator deve ser considerado para fins de determinação de etapas de reaquecimentos do billet e obtenção de uma microestrutura final desejada. 

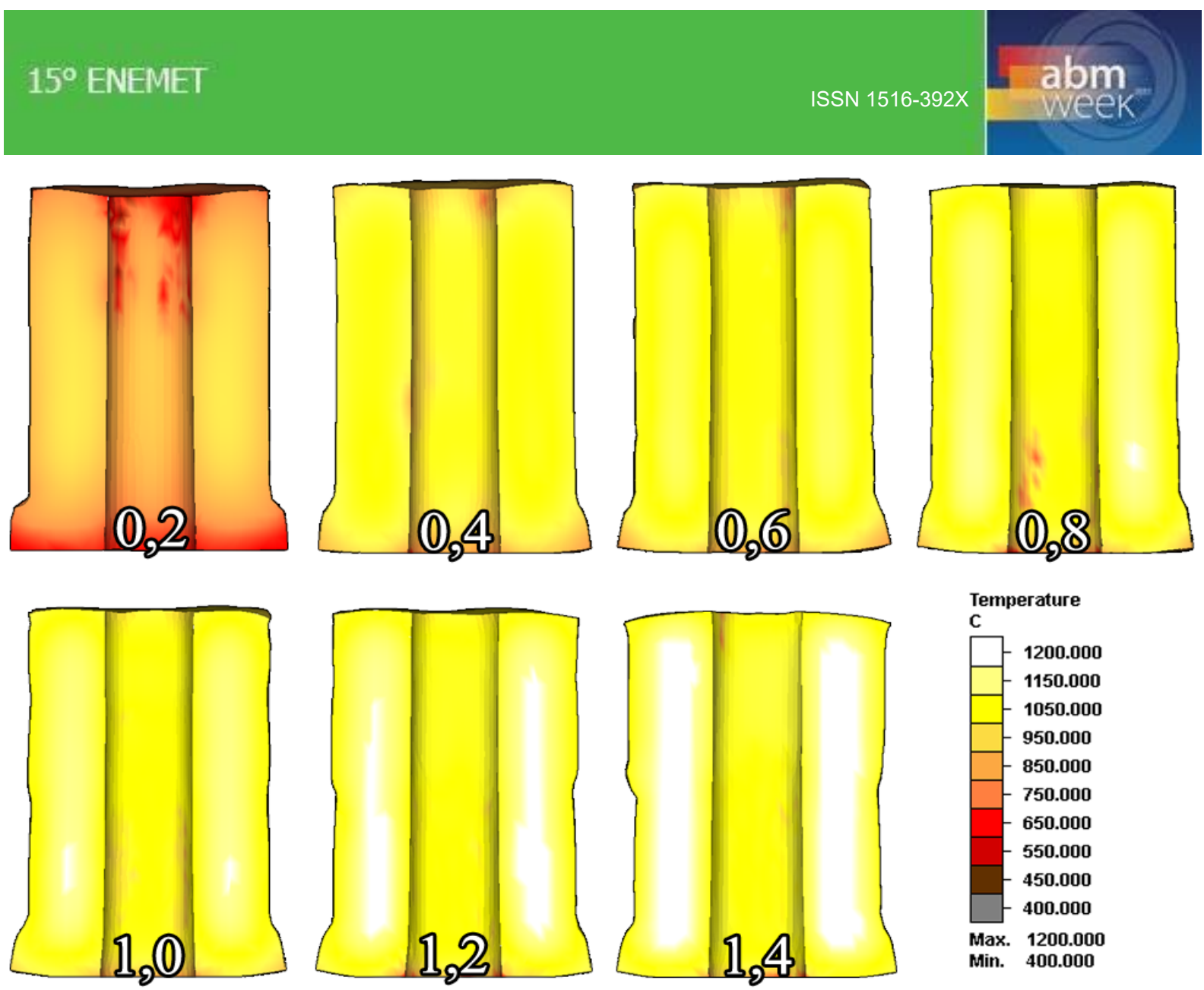

Figura 8. Distribuição de temperaturas para os processos.

\section{CONCLUSÃO}

O uso de simulações numéricas pelo método de elementos finitos mostrou-se bastante eficaz para o estudo do efeito da razão $S_{B} / h o$ nos processos de forjamento de eixos vazados. Os padrões de deformação, que dificilmente poderiam ser obtidos através de experimentos físicos, puderam ser analisados e comparados com os já existentes na literatura. Através desta análise, foi possível observar o comportamento do fluxo de material para este modelo de processo e determinar uma faixa aceitável de valores para os quais os resultados são mais satisfatórios.

A similaridade com os processos de forjamento de peças maciças foi confirmada, tendo, em ambos os casos, as duas matrizes agindo como par ação e reação na superfície da peça, determinando, assim, o modelo de deformação no material. No entanto, pôde-se observar o efeito que o mandril acarreta no processo e, a partir disto, determinar quais mudanças no valor da razão de mordida, em relação aos sugeridos na literatura para o forjamento de peças maciças, deveriam ser realizadas visando à obtenção de um núcleo com deformações homogêneas para os eixos vazados forjados.

A razão de mordida a ser utilizada nos processos com eixos vazados é menor que o valor considerado ideal para os maciços. Enquanto no último caso o valor deve estar entre 0,5 e 0,8 , a razão ideal para a peça não maciça estudada neste trabalho deve estar em torno de 0,4 . 


\section{Agradecimentos}

Os autores agradecem ao projeto BRAGECRIM (Iniciativa Brasil-Alemanha para Pesquisa Colaborativa em Tecnologia de Manufatura), ao Conselho Nacional de Desenvolvimento Científico e Tecnológico (CNPq) e à Coordenação de Aperfeiçoamento de Pessoal de Nível Superior (CAPES) pelo financiamento das bolsas de estudo, ao Laboratório de Transformação Mecânica (LdTM) e à Universidade Federal do Rio Grande do Sul (UFRGS).

\section{REFERÊNCIAS}

1. SCHAEFFER, L., "Forjamento, Introdução ao Processo", Imprensa Livre, Porto Alegre, 2006.

2. CHEN, K., YANG, Y., SHAO, G., LIU, K., Simulation of large forging flat-anvil stretching process and its optimization". Journal of Shanghai Jiaotong University, China, 2011.

3. KAKIMOTO, H., ARIKAWA, T., TAKAHASHI, Y., TANAKA, T., IMAIDA, Y., "Development of forging process design to close internal voids". Journal of Materials Processing Technology, Japan, 2010.

4. CHO, J.R, PARK, C.Y., YANG, D.Y., "Investigation of the cogging process by threedimensional thermo-viscoplastic finite element analysis", Journal of Engineering Manufacture, 1992.

5. KIM, P.H., CHUN, M.S., YI, J.J., MOON, Y.H., "Pass schedule algorithms for hot open die forging", Journal of Material Processing Technology 130-131, pag. 516-523, 2002.

6. CETLIN, P. R., HELMANN, H., "Fundamentos da Conformação Mecânica dos Metais". São Paulo, Artliber Editora, 2005.

7. SHAH, K. N., KIEFER, B. V., GAVIGAN, J. J., "Finite element simulation of internal void closure in open-die press forging", Advanced Manufacturing Processes, vol 1, 1986.

8. WOLSKE, M., "Umformbarkeit und Modellierung der Gefügeentwicklung von Nickelbasislegierungen." RWTH Aachen, Shaker Verlag, 2005.

9. SPUR, G., NEUGEBAUER, R., HOFFMANN, H., "Handbuch Umformen". Carl Hanser Verlag, Alemanha, 2012. 